\title{
Flowsheet simulation of cobalt-nickel separation by solvent extraction with trihexyl(tetradecyl)phosphonium chloride
}

DOI:

10.1021/acs.iecr.7b05254

\section{Document Version}

Accepted author manuscript

Link to publication record in Manchester Research Explorer

Citation for published version (APA):

Chen, H., Jobson, M., Masters, A., Gonzalez Miquel, M., \& Halstead, S. (2018). Flowsheet simulation of cobalt-nickel separation by solvent extraction with trihexyl(tetradecyl)phosphonium chloride. Industrial and Engineering Chemistry Research, 57(30). https://doi.org/10.1021/acs.iecr.7b05254

Published in:

Industrial and Engineering Chemistry Research

\section{Citing this paper}

Please note that where the full-text provided on Manchester Research Explorer is the Author Accepted Manuscript or Proof version this may differ from the final Published version. If citing, it is advised that you check and use the publisher's definitive version.

\section{General rights}

Copyright and moral rights for the publications made accessible in the Research Explorer are retained by the authors and/or other copyright owners and it is a condition of accessing publications that users recognise and abide by the legal requirements associated with these rights.

\section{Takedown policy}

If you believe that this document breaches copyright please refer to the University of Manchester's Takedown Procedures [http://man.ac.uk/04Y6Bo] or contact uml.scholarlycommunications@manchester.ac.uk providing relevant details, so we can investigate your claim.

\section{OPEN ACCESS}




\title{
Flowsheet simulation of cobalt-nickel separation by
}

\author{
solvent extraction with
}

\section{trihexyl(tetradecyl)phosphonium chloride}

Hongyan Chen*, Megan Jobson, Andrew J. Masters, Maria Gonzalez-Miquel, Simon Halstead

School of Chemical Engineering and Analytical Science, The University of Manchester, Manchester, M13 9PL, UK

KEYWORDS ionic liquids, Cyphos 101, liquid-liquid extraction, hydrochloric acid, gPROMS, COSMO

ABSTRACT Solvent extraction is widely used for selective separation of metals from solutions. Ionic liquids are showing potential for this purpose. To date, little research has focused on design, operation and optimization of solvent extraction flowsheets using ionic liquids. This work addresses this gap in knowledge, aiming to support development, design and optimization of such solvent extraction processes. In this work, a general flowsheet simulation model is developed and applied for the case of cobalt-nickel separation using ionic liquid

\footnotetext{
*Corresponding author, email: Hongyan.chen@manchester.ac.uk
} 
trihexyl(tetradecyl)phosphonium chloride $\left(\left[\mathrm{P}_{66614}\right] \mathrm{Cl}\right)$. All components are treated as distributing between the two phases and are modelled using distribution coefficient models derived from published experimental data and ab initio computational results. The rate of mass transfer between the two phases is calculated using a mass transfer model. Simulation results are shown to be generally in good agreement with published experimental results.

\section{INTRODUCTION}

Demand for strategically-important metals such as rare earths, nickel and cobalt is rising due to increasing global populations and because of the move towards low-carbon technologies, following the Paris Climate Agreement. ${ }^{1}$ To secure the supply of these strategic metals in future, they need to be recovered from wastes and recycled using technologies with low environmental impact. Such technologies are therefore attracting significant research interest. ${ }^{2-4}$ Hydrometallurgical methods have been widely used for metals separations for many years. ${ }^{5}$ However, hydrometallurgical separation of cobalt from nickel, for example, is highly challenging because of their similar chemical properties and similar behavior in aqueous solutions. Traditionally, cobalt and nickel are separated by selective oxidation and precipitation processes that have low efficiency and low selectivity. ${ }^{6}$ Solvent extractions can separate metals selectively and with high yields. ${ }^{7}$ Several researchers have investigated the use of solvent extraction to separate cobalt and nickel. ${ }^{8-10}$ However, conventional solvents are usually noxious and/or flammable; it is necessary to replace these with more environmentally benign solvents, to reduce the environment impact of the metal separation process. 
Ionic liquids are gaining favor as environmentally-friendly solvents, offering advantages because of their low vapor pressure and low flammability. Ionic liquids can also be tailored to a given application to achieve high selectivity. They thus could have potential to replace flammable, volatile and toxic organic solvents conventionally used for metal extraction. ${ }^{11,12}$ Several research publications have investigated this possibility. For example, extraction of rare earths using tricaprylmethylammonium nitrate and di(2-ethylhexyl) 2-ethylhexyl phosphonate; ${ }^{13}$ using bifunctional ionic liquids to separate lanthanum from other rare earths, using a 'molecular' extraction mechanism; ${ }^{14}$ back-washing uranium from a loaded ionic liquid using aqueous $\mathrm{NaOH}$ solution; ${ }^{15}$ applying tetraoctylphosphonium oleate to separate cobalt and sodium. ${ }^{16}$

Hydrophobic phosphonium ionic liquids, such as trihexyl(tetradecyl)phosphonium chloride $\left(\left[\mathrm{P}_{66614}\right] \mathrm{Cl}\right.$, Cyphos IL $\left.101^{\circledR}\right)$, have attracted significant attention, due to their low price, high stability and low solubility in water. ${ }^{17}$ Examples of metal separations using this ionic liquid include the recovery of zinc,${ }^{18}$ actinides, ${ }^{19}$ iron, ${ }^{20}$ mercury, ${ }^{21}$ and cobalt ${ }^{22,23}$ from chloride solutions. By an anion exchange process, $\left[\mathrm{P}_{66614}\right] \mathrm{Cl}$ can be easily modified, to replace its anion to synthesize other trihexyl(tetradecyl)phosphonium ionic liquids; these can be used in other metal separation processes, such as for separation of mixtures of rare earths. ${ }^{24,25}$ Although the viscosity of pure $\left[\mathrm{P}_{66614}\right] \mathrm{Cl}$ is high, it reduces significantly with increasing temperature and increasing water content. ${ }^{26}$ Solvent extractions typically involve an aqueous phase and a solvent phase; therefore, the ionic liquid solution is always saturated with water. The saturation with water makes it possible to use $\left[\mathrm{P}_{66614}\right] \mathrm{Cl}$ in solvent extraction without other diluents, at slightly raised temperatures. ${ }^{27-29}$ The environmental impact of additional diluents may thus be avoided.

Separation of cobalt and nickel by $\left[\mathrm{P}_{66614}\right] \mathrm{Cl}$ was also investigated. ${ }^{22,23,27,29}$ Researchers published experimental data for cobalt extracted by $\left[\mathrm{P}_{66614}\right] \mathrm{Cl}$ at various conditions and 
confirmed the cobalt can be extracted by $\left[\mathrm{P}_{66614}\right] \mathrm{Cl}$ in the form of $\mathrm{CoCl}_{4}^{2-} \cdot{ }^{22,25,27}$ Wellens et al. ${ }^{29}$ also presented experimental results of a continuous flowsheet for $\mathrm{Co}-\mathrm{Ni}$ separation using pure $\left[\mathrm{P}_{66614}\right] \mathrm{Cl}$ and countercurrent extraction units (effectively stirred mixer-settler units). However, there is relatively little focus on how differences between the properties of Co and Ni can be best exploited in practice. The reported results ${ }^{22,23,27,29}$ are focused on cobalt extraction, but little information is provided about the distribution of other components, for example, how hydrochloric acid distributes between the aqueous and ionic liquid phases. In addition, the experiments did not consider some important physical properties such as density, viscosity, diffusion and interfacial tension for both phases, and how these change within the extraction process.

The value of flowsheet simulation for design, development and optimization of solvent extraction processes separating metals is well known. ${ }^{30}$ This work therefore aims to develop and apply a flowsheet simulation model for the extractive separation of highly similar transition metals, namely cobalt and nickel, using an ionic liquid. The work aims to extend the state of the art in process modelling and simulation of such flowsheets. Development of the process model requires selection and/or development of suitable models for the physical properties and distribution coefficients of the mixtures involved, for relevant mass transfer phenomena, for individual extraction units and for the multi-stage extraction flowsheet.

\section{MODEL DEVELOPMENT}

\subsection{Simulation Model Overview}

The flowsheet simulation model has a hierarchical structure, as shown in Scheme 1. A database of key physical properties of constituent species underpins the model. The distribution of species between the two phases and the physical properties of each phase, considering 
temperature and composition dependence, are described by models of physical and chemical phenomena. A mass transfer model represents mass transfer between the two phases by solvent extraction in a mixer-settler extraction unit. The model for a mixer-settler with one inlet and one outlet for each phase is constructed by combining these models. The simulation model for the whole flowsheet is obtained by connecting the mixer-settler models to account for material flows between extraction units. The flowsheet model is, in principle, generic; to represent other extraction processes, appropriate models of the physical and chemical phenomena are required, and the connections between extraction units need to be tailored to the flowsheet configuration of interest. Current work is adapting this modelling framework for development and design of flowsheets for extractive separation of rare earths using ionic liquids. The flowsheet model is implemented in gPROMS simulation software which supports both steady state and dynamic simulations and various operational modes.

Scheme 1. Flowsheet model structure

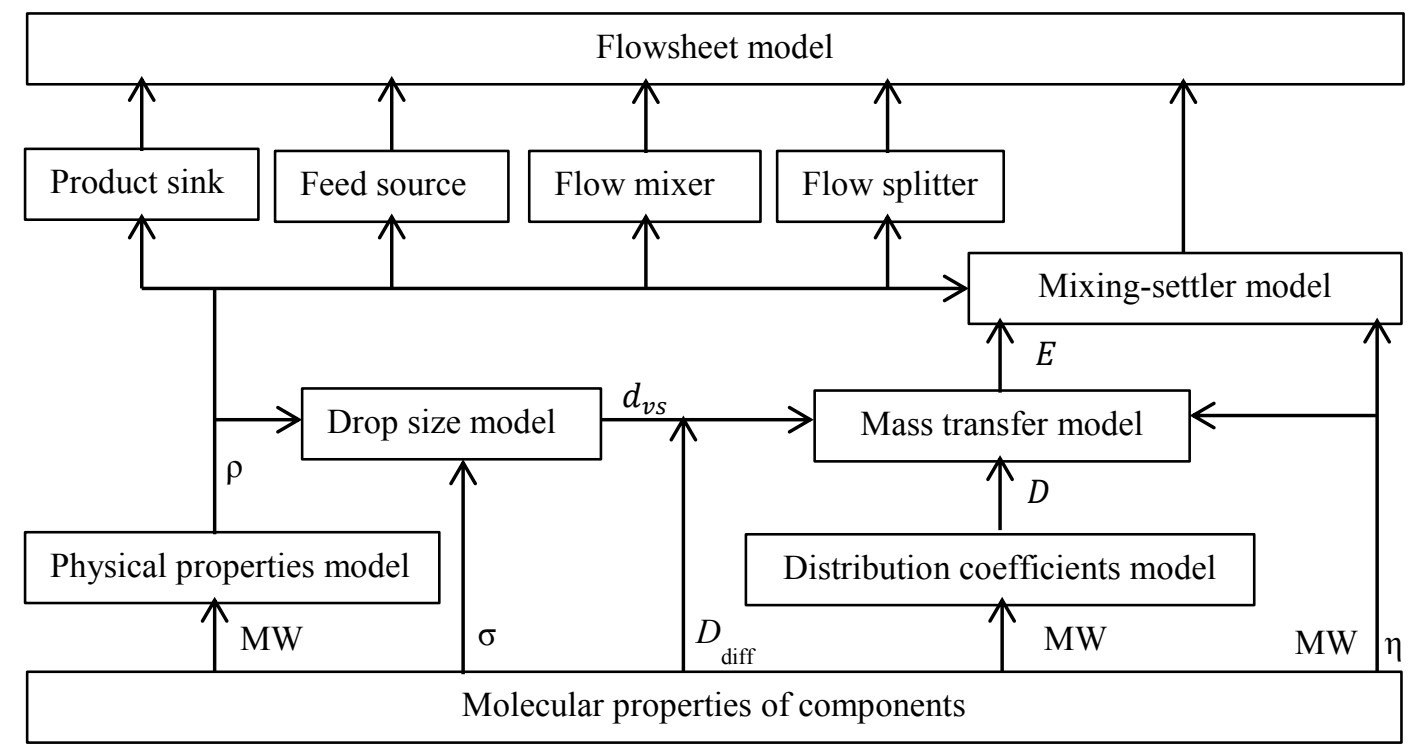

The phase equilibrium models assume that only two liquid phases exist: the low vapor pressure of the ionic liquid implies that the vapor phase does not need to be modelled if the extraction 
process takes place at atmospheric pressure. Like many solvent extraction flowsheet models, ${ }^{31,32}$ enthalpy changes are also neglected; this assumption is justified by the relatively small enthalpy changes involved and the absence of significant enthalpy changes arising from evaporation or condensation.

\subsection{Distribution Coefficient Models}

A distribution coefficient model predicts the distribution of species between the two phases at equilibrium. It is known that cobalt can form several chloro-complexes in chloride solutions: ${ }^{33-35}$ $\mathrm{Co}^{2+}+\mathrm{i} \mathrm{Cl}^{-} \rightleftharpoons \mathrm{CoCl}_{\mathrm{i}}^{2-\mathrm{i}}$, where $i=1-4$

The corresponding equilibrium constant is given by:

$\beta_{\mathrm{i}}=\frac{\mathrm{C}_{\mathrm{CoCll}_{\mathrm{i}}^{2-\mathrm{i}}}}{\mathrm{C}_{\mathrm{Co}^{2}+} \cdot \mathrm{C}_{\mathrm{Cl}^{-}}^{\mathrm{i}}}$

where $\mathrm{C}$ represents the concentration of the ion in aqueous solution in $\mathrm{mol} \mathrm{L}^{-1}$.

The extraction of metal by phosphonium ionic liquids occurs via an anion exchange mechanism. ${ }^{36}$ Therefore the reaction that represents the extraction of cobalt chloride by $\left[\mathrm{P}_{66614}\right] \mathrm{Cl}$ can be expressed as: $:^{22,25,27}$

$\mathrm{CoCl}_{4}^{2-}+2 \overline{\left[\mathrm{P}_{66614}\right] \mathrm{Cl}} \rightleftharpoons \overline{\left[\mathrm{P}_{66614}\right]_{2} \mathrm{CoCl}_{4}}+2 \mathrm{Cl}^{-}$

The equilibrium constant for reaction (3) is therefore given by:

$K_{\mathrm{D}}=\frac{\overline{\mathrm{C}}_{\mathrm{Co}} \cdot \mathrm{C}_{\mathrm{Cl}}^{2-}}{\overline{\mathrm{C}}_{\mathrm{IL}}^{2} \cdot \mathrm{C}_{\mathrm{CoCl}_{4}^{2-}}}$

where the overbar represents the properties in ionic liquid phase, therefore, $\overline{\mathrm{C}}$ represents the concentration of species in ionic liquid phase, and IL represents the metal-free (unloaded) ionic liquid $\left[\mathrm{P}_{66614}\right] \mathrm{Cl}$.

The distribution coefficient is defined by the ratio of concentrations of the species of interest between the ionic liquid and aqueous phases: 


$$
\mathrm{D}_{\mathrm{Co}}=\frac{\overline{\mathrm{C}}_{\mathrm{Co}}}{\mathrm{C}_{\mathrm{Co}^{2}+}+\sum_{\mathrm{i}=1}^{4} \mathrm{CoCl}_{\mathrm{i}}^{2-\mathrm{i}}}
$$

The extraction mechanism of cobalt from chloride solution by tricaprylmethylammonium chloride is similar to reaction (3). ${ }^{38}$ Considering non-ideal and salt effects ${ }^{37}$, Sato et al. ${ }^{38}$ proposed a semi-empirical equation to calculate the distribution coefficient of cobalt between chloride aqueous solution and tricaprylmethylammonium chloride at various chloride concentrations:

$\mathrm{D}_{\mathrm{Co}}=\frac{k^{\prime} \mathrm{e}^{p_{1} \mathrm{C}_{\mathrm{Cl}^{-}+p_{2}} \mathrm{C}_{\mathrm{Cl}}^{2}}}{\left(1+\sum_{\mathrm{i}=1}^{4} \beta_{\mathrm{i}} \mathrm{C}_{\mathrm{Cl}^{-}}^{\mathrm{i}}\right)} \cdot \mathrm{C}_{\mathrm{Cl}^{-}}^{2} \cdot \overline{\mathrm{C}}_{\mathrm{IL}}^{2}$

In which $k^{\prime}, p_{1}$, and $p_{2}$ are adjustable parameters that represent the effects of non-ideality (related to activity coefficients) and salting-out. These parameters and the equilibrium constants, $\beta_{i}$, are regressed against experimental results. ${ }^{27}$ The regressed parameter values are listed in Table 1.

Table 1 Parameters of distribution coefficient model for cobalt

\begin{tabular}{lll}
\hline Parameter & Value & Units \\
\hline$k^{\prime}$ & 1.082 & $\mathrm{~mol}^{-4} \mathrm{~L}^{4}$ \\
$p_{1}$ & 1.584 & $\mathrm{~mol}^{-1} \mathrm{~L}$ \\
$p_{2}$ & -0.09763 & $\mathrm{~mol}^{-2} \mathrm{~L}^{2}$ \\
$\beta_{1}$ & 3.388 & $\mathrm{~mol}^{-1} \mathrm{~L}$ \\
$\beta_{2}$ & 1.245 & $\mathrm{~mol}^{-2} \mathrm{~L}^{2}$ \\
$\beta_{3}$ & 0.02590 & $\mathrm{~mol}^{-3} \mathrm{~L}^{3}$ \\
$\beta_{4}$ & 0.02118 & $\mathrm{~mol}^{-4} \mathrm{~L}^{4}$ \\
\hline
\end{tabular}

\footnotetext{
Nickel is scarcely extracted by $\left[\mathrm{P}_{66614}\right] \mathrm{Cl}^{25,27,39}$ To simplify calculations, the distribution coefficient of nickel is calculated by a linear empirical equation obtained from experimental results $^{27}$ :
} 


$$
\mathrm{D}_{\mathrm{Ni}}=1.061 \times 10^{-3} \mathrm{C}_{\mathrm{Cl}^{-}}+3.039 \times 10^{-4}
$$

The distribution coefficients of cobalt and nickel predicted using Eq.(6) and Eq.(7) are compared to published experimental data ${ }^{27}$ in Figure 1.

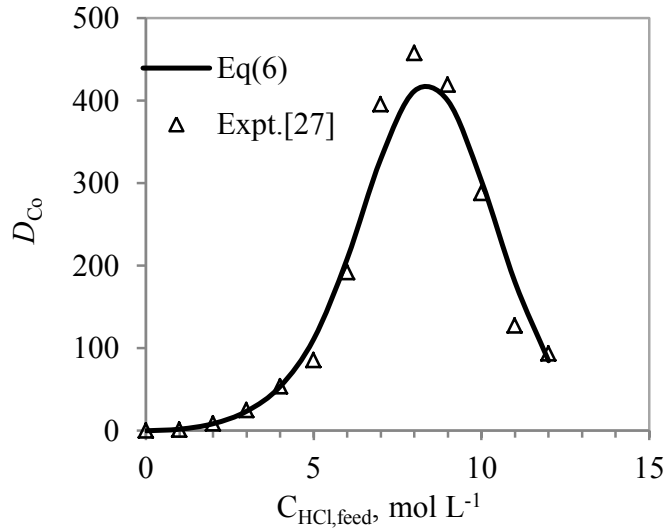

(a)

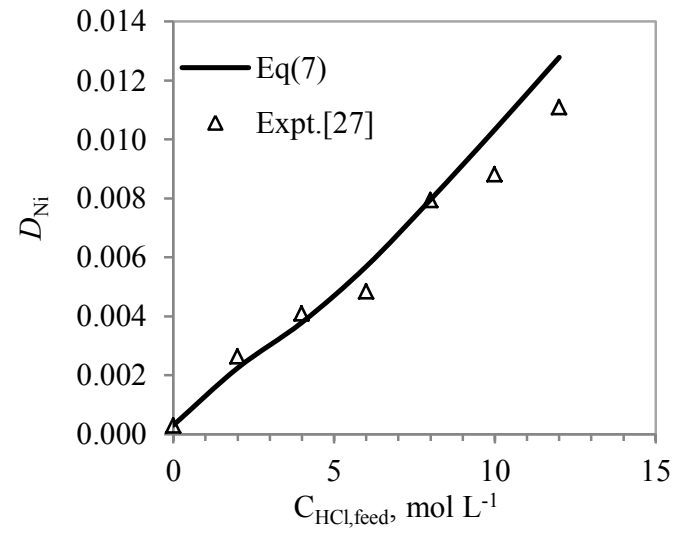

(b)

Figure 1 Distribution coefficient models: (a) Cobalt; (b) Nickel

The distribution of cobalt from chloride solutions to the ionic liquid $\left[\mathrm{P}_{66614}\right] \mathrm{Cl}$ is sensitive to the concentration of chloride. ${ }^{22,27}$ In several published studies, ${ }^{18,20,22,25,27} \mathrm{HCl}$ is used to control the concentration of chloride in the aqueous phase. However, $\mathrm{HCl}$ is also extracted by $\left[\mathrm{P}_{66614}\right] \mathrm{Cl}^{22,27}$ therefore a distribution coefficient model for $\mathrm{HCl}$ is essential.

Good et al. ${ }^{40}$ proposed that $\mathrm{HCl}$, in the form of $\mathrm{HCl}_{2}^{-}$, can be extracted by tricaprylylmonomethyl ammonium chloride (A336) by an anion exchange mechanism. Neutron diffraction experiments showed that $\mathrm{HCl}_{2}^{-}$is present in 1-ethyl-3-methylimidazolium ionic liquids in an asymmetric form. ${ }^{41}$ Del Popolo et al. ${ }^{42}$ used an ab initio molecular dynamics simulation method to obtain the same result. For $\left[\mathrm{P}_{66614}\right] \mathrm{Cl}$, Quinn et al. ${ }^{19}$ proposed that the reaction leading to extraction of $\mathrm{HCl}$ by $\left[\mathrm{P}_{66614}\right] \mathrm{Cl}$ can be expressed by:

$\mathrm{H}^{+}+\mathrm{Cl}^{-}+\overline{\left[\mathrm{P}_{66614}\right] \mathrm{Cl}} \rightleftharpoons \overline{\left[\mathrm{P}_{66614}\right] \mathrm{HCl}_{2}}$

The reaction equilibrium constant for $\mathrm{HCl}$ extraction can then be represented by: 
$\mathrm{K}_{\mathrm{D}_{\mathrm{H}}}=\frac{\overline{\mathrm{C}}_{\mathrm{HCL}}}{\overline{\mathrm{C}}_{\mathrm{IL}} \cdot \mathrm{C}_{\mathrm{Cl}^{-} \cdot \mathrm{C}_{\mathrm{H}^{+}}}}$

Considering non-ideal effects, and neglecting the difference between the activity coefficients of the ionic liquid and of $\mathrm{HCl}$ in the ionic liquid phase, i.e., assuming $\bar{\gamma}_{\mathrm{IL}} / \bar{\gamma}_{\mathrm{HCl}} \approx 1$, the distribution coefficient of $\mathrm{HCl}$ is given by:

$\mathrm{D}_{\mathrm{H}}=\mathrm{K}_{\mathrm{D}_{\mathrm{H}}} \cdot \overline{\mathrm{C}}_{\mathrm{IL}} \cdot \mathrm{C}_{\mathrm{Cl}^{-}} \cdot \gamma_{ \pm \mathrm{H}}^{2}$

where $\gamma_{ \pm H}$ is mean activity coefficient of hydrochloric acid, and is calculated by an extended Debye-Hückel equation. The Debye-Hückel equation has been used to calculate the effects of non-ideality in electrolyte solutions. ${ }^{19,43}$ It is based on three assumptions: all ions can be considered as point charges, the only interactions between ions are electrostatic, and the effect of counterions, on a particular ion, can be described in terms of a static ion-cloud. ${ }^{44}$ However, this equation is only correct when the solution is very dilute. In concentrated solutions, extra terms, regressed from experimental data, are usually needed to correct the Debye-Hückel predictions. Partanen et al. ${ }^{45}$ published an extended Debye-Hückel equation which can predict activity coefficients of hydrochloric acid aqueous solution up to $16 \mathrm{~mol} \mathrm{~kg}^{-1}$ and $50{ }^{\circ} \mathrm{C}$ with relatively simple equations. The relative error of this equation to literature data ${ }^{46}$ at $75^{\circ} \mathrm{C}$ up to $7 \mathrm{~mol} \mathrm{~kg}^{-1}$ is less than $3 \%$ and at $45{ }^{\circ} \mathrm{C}$ in same concentration range is around $4 \%$. Because this simulated flowsheet is operated at $8 \mathrm{M} \mathrm{HCl}$ and $60{ }^{\circ} \mathrm{C}$, this equation is used for the calculation of the mean activity coefficient of $\mathrm{HCl}$ in aqueous solution as follows:

$\ln \gamma_{ \pm H}=-\frac{3 A_{\varnothing} \sqrt{m}}{1+B \sqrt{m}}+h_{1}\left(\frac{m}{m^{0}}\right)+b_{2}\left(\frac{m}{m^{0}}\right)^{2}+b_{3}\left(\frac{m}{m^{0}}\right)^{\frac{7}{2}}-\ln (1+2 \times 0.018015 m)$

where $A_{\varnothing}$ is the Debye-Hückel parameter that is dependent on the temperature, ${ }^{47} \mathrm{~m}$ is the ionic strength, expressed in units of molarity, and $\mathrm{m}^{0}=1 \mathrm{~mol} \mathrm{~kg}^{-1} .{ }^{45}$ The values of parameters $B, h_{1}, b_{2}$, and $b_{3}$ may be obtained from the literature: ${ }^{45}$

$B=1.4 \mathrm{~mol}^{-0.5} \mathrm{~kg}^{0.5}, h_{1}=0.33866-0.001283(\mathrm{~T}), b_{2}=0.006, b_{3}=-9.7 \times 10^{-5}$ 
$T$ is temperature in ${ }^{\circ} \mathrm{C}$.

The equilibrium constant, $K_{\mathrm{D}_{\mathrm{H}}}$, which is estimated from experimental data ${ }^{27,29}$, is 0.0964 .

It is known that water will transfer from the aqueous phase to the ionic liquid during the extraction process. It is also known that the water concentration in $\left[\mathrm{P}_{66614}\right] \mathrm{Cl}$ is not constant during the extraction process. ${ }^{27,29}$ However, experimental data for the water concentration in the ionic liquid phase are lacking; therefore, the quantum chemical equilibrium thermodynamics method COSMO-RS (COnductor-like Screening MOdel for Realistic Solvents) ${ }^{48,49}$ is applied to estimate the amount of water present in the ionic liquid phase at equilibrium. This method computes the screening charge density on the molecular surface based on unimolecular quantumchemical calculations, and then applies a statistical thermodynamic approach to estimate the chemical potential of the species in solution and the related equilibrium thermodynamic properties of the fluid mixture. In this method, the COSMO file which is the profile of surface charge of the molecular is obtained from quantum chemical calculation. The thermodynamics properties then are calculated by statistical thermodynamics from this COSMO file. In this work, COSMO-RS is selected to estimate the concentration of water in the ionic liquid phase because this method has proven useful in estimating the VLE of water-ionic liquid systems, as demonstrated by the study of Freire et al ${ }^{50}$ In addition, Aspen Plus conveniently includes COSMO based model as a physical property estimation method. ${ }^{51}$

Figure 2 shows the water content in the ionic liquid $\left[\mathrm{P}_{66614}\right] \mathrm{Cl}$ at various $\mathrm{HCl}$ concentrations, as calculated by Aspen Plus, using the COSMO-based model. COSMO files are retrieved from the COSMOlogic database. It may be seen that the Aspen Plus predictions are in reasonable agreement with experimental data for the cases of no $\mathrm{HCl}$ and $8 \mathrm{M} \mathrm{HCl}$ in the aqueous phase. 
The Aspen Plus predictions can then be represented simply using a regressed quadratic model that is easily incorporated into the flowsheet model implemented in gPROMS:

$D_{W}=\left(6.544 \times 10^{-4} C_{H}^{2}-9.654 \times 10^{-3} C_{H}+0.1275\right) \frac{\bar{c}_{I L}}{\bar{C}_{I L}{ }^{0}}$

where $\bar{C}_{I L^{0}}$ is the total ionic liquid concentration in the ionic liquid phase.

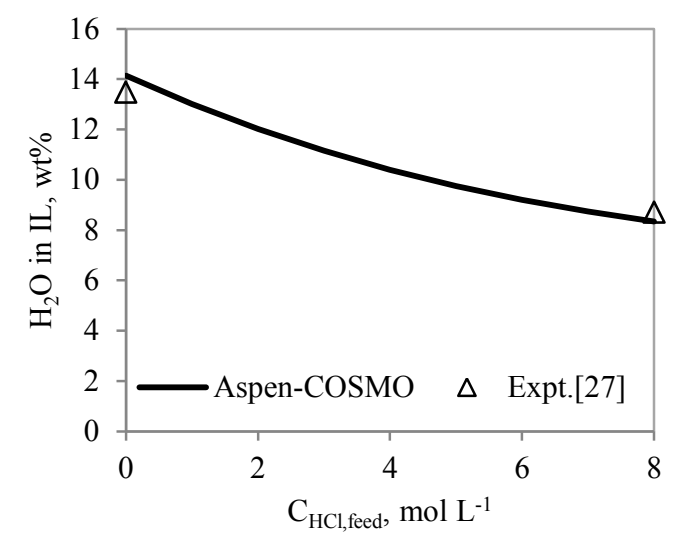

Figure 2 Water in $\left[\mathrm{P}_{66614}\right] \mathrm{Cl}$ at equilibrium

$\left[\mathrm{P}_{66614}\right] \mathrm{Cl}$ is almost completely absent from the aqueous phase, whether or not salt ions are

present. ${ }^{36}$ However, published experimental results ${ }^{29}$ show that 0.04 to $0.05 \mathrm{~g} \mathrm{~L}^{-1}$ of ionic liquid is lost to the aqueous phase; therefore, the distribution coefficient (the ratio of concentration in the ionic liquid to the aqueous phase) is set to $1.6 \times 10^{4}$ for $\left[\mathrm{P}_{66614}\right] \mathrm{Cl}$ in the simulation model.

\subsection{Physical Properties Modelling and Calculation}

To model the metal extraction process, physical properties such as density, viscosity, diffusion coefficient, and interfacial tension need to be predicted.

Experimental data for the density of various aqueous solutions of cobalt chloride, nickel chloride and hydrochloride, at various temperatures, are available, as summarised in Table S1 in the Supporting Information. These data are used in this work to regress an empirical model for the density $\left(\mathrm{g} \mathrm{L}^{-1}\right)$ of an aqueous solution containing cobalt chloride, nickel chloride and hydrochloride: 


$$
\begin{aligned}
& \rho_{a q}=\left(997.0+15.80 C_{\mathrm{HCl}}+115.4 C_{N i}+113.5 C_{C o}\right) \cdot(1-0.0013(T-25))+ \\
& 0.9208(T-25)
\end{aligned}
$$

Figure 3 shows that this simple model is in good agreement with the published data ${ }^{52-56}$ over the range of concentrations considered. The percentage average absolute deviation (\%AAD) of the predictions is $2.5 \%$, while the maximum relative error is $5 \%$.

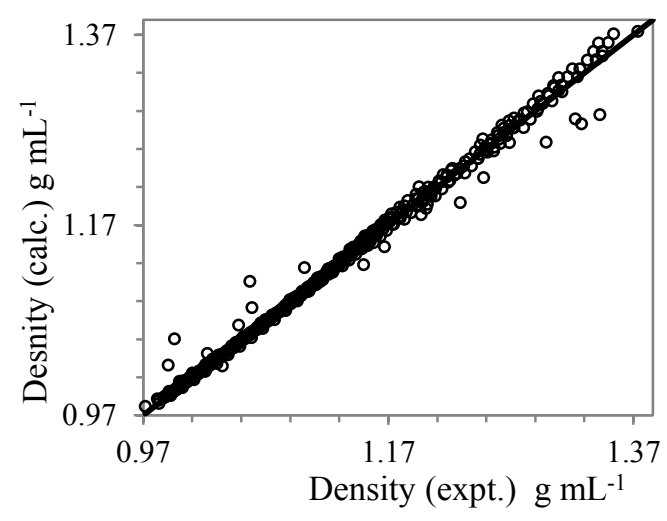

Figure 3 Validation of aqueous phase density model

Some published and experimental data are available for the density of ionic liquid solutions; these data show that the density is somewhat sensitive to the water, $\mathrm{HCl}$ and metals content. A simple linear correlation is regressed against experimental measured and published data ${ }^{27,29}$. The density of ionic liquid solutions at $60^{\circ} \mathrm{C}$ is given by:

$\rho_{\mathrm{IL}}=\left(\rho_{\mathrm{IL}}^{\mathrm{s}, 60}+0.00052 \times w \mathrm{t} \% \mathrm{H}_{2} \mathrm{O}+0.0053 \times \mathrm{wt} \% \mathrm{HCl}-0.018\left(\overline{\mathrm{C}}_{\mathrm{Co}}+\overline{\mathrm{C}}_{\mathrm{Ni}}\right)\right)$

where $\rho$ is density $\left(\mathrm{g} \mathrm{mL}^{-1}\right)$ and $\rho_{I L}^{s, 60}$ is the density of pure $\left[\mathrm{P}_{66614}\right] \mathrm{Cl}$ at $60^{\circ} \mathrm{C}\left(0.8695 \mathrm{~g} \mathrm{~mL}^{-1}\right) .^{26}$ Figure 4 shows that the density predicted by eq. (14) is within $1 \%$ of measured values.

The density of pure $\left[\mathrm{P}_{66614}\right] \mathrm{Cl}$ at temperature $\mathrm{T}\left({ }^{\circ} \mathrm{C}\right)$ can be estimated by: ${ }^{26}$

$\rho_{I L}^{S, T}=\rho_{I L}^{s, 60} e^{-6.525 \times 10^{-4}(T-60)}$ 
It is assumed that the effect of water, $\mathrm{HCl}$ and metals on the density of the solution is not temperature dependent. Therefore, $\rho_{I L}^{s, 60}$ in equation (14) can be replaced by $\rho_{I L}^{s, T}$ in equation (15) to calculate the viscosity of ionic liquid phase at temperature $\mathrm{T}$.

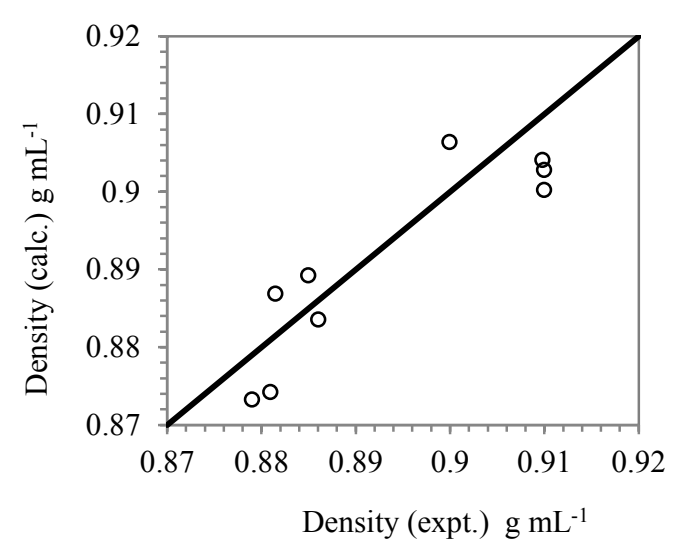

Figure 4 Validation of ionic liquid phase density model at $60^{\circ} \mathrm{C}$

The viscosity of $\left[\mathrm{P}_{66614}\right] \mathrm{Cl}$ is sensitive to temperature; therefore, the extraction process should be operated at moderately high temperatures, e.g. $60^{\circ} \mathrm{C}$, to maintain a relatively low viscosity and thus facilitate mass transfer. ${ }^{27}$ In the extraction process, the ionic liquid phase is saturated with water; published results of extraction experiments using ionic liquid $\left[\mathrm{P}_{66614}\right] \mathrm{Cl}$, aqueous $\mathrm{HCl}$ and various cobalt loadings ${ }^{27}$ permit regression of correlations for the viscosity of the ionic liquid at $60^{\circ} \mathrm{C}$ :

$\ln \bar{\eta}=3.376 \overline{\mathrm{C}}_{\mathrm{Co}}^{2}+0.8487 \overline{\mathrm{C}}_{\mathrm{Co}}+\ln \bar{\eta}^{0}$

where $\bar{\eta}^{0}$ is the viscosity of the ionic liquid saturated by aqueous hydrochloric acid (without metals).

Published results of viscosity measurements are available ${ }^{27}$ for the ionic liquid phase in the context of metal-free ionic liquid-aqueous $\mathrm{HCl}$ phase equilibrium experiments, where the aqueous phase was $8 \mathrm{M} \mathrm{HCl}$. A simple linear interpolation, regressed to these results, represents 
the dependence of the ionic liquid viscosity on the concentrations of water and $\mathrm{HCl}$ in the ionic liquid phase.

$\bar{\eta}^{0}=240.37 \frac{\overline{\mathrm{C}}_{\mathrm{IL}}}{\overline{\mathrm{C}}_{\mathrm{IL}}+\overline{\mathrm{C}}_{\mathrm{H}_{2} \mathrm{O}}+\overline{\mathrm{C}}_{\mathrm{HCl}}}+46.374$

\subsection{Mass Transfer Model}

The mass transfer model is based on a linear driving force model, as these are widely used in

solvent extraction process models. ${ }^{57-59}$ The rate of mass transfer between the aqueous phase and ionic liquid phase can be expressed as:

$$
\mathrm{E}=\mathrm{K}_{\mathrm{OO}} \mathrm{V} a\left(\overline{\mathrm{C}}^{*}-\overline{\mathrm{C}}\right)
$$

Where $K_{\mathrm{OO}}$ is the overall mass transfer coefficient; $V$ is the total volume of liquid in the extractor, $a$ is the interfacial area for mass transfer per unit volume of liquid; $\bar{C}^{*}$ is the concentration of the solute in the ionic liquid phase in equilibrium with the concentration of this solute in the aqueous phase; $\bar{C}$ is the concentration of this solute in ionic liquid phase. The interfacial area, $a$, is calculated from the volume fraction of the dispersed phase $\emptyset_{\mathrm{d}}$ and the surface-mean diameter (or Sauter mean diameter) of the droplets of the dispersed phase, $d_{\mathrm{vs}}$ :

$a=\frac{6 \emptyset_{d}}{d_{v s}}$

The surface-mean diameter $d_{v s}$ depends on the Weber number: ${ }^{60}$

$$
\mathrm{N}_{\mathrm{We}}=\frac{\mathrm{D}_{\mathrm{i}}^{3} \omega^{2} \rho_{\mathrm{c}}}{\sigma}
$$

where $D_{\mathrm{i}}$ is the diameter of the impeller, $\omega$ is the rotation speed of the impeller, $\rho_{c}$ is the density of continuous phase and $\sigma$ is the interfacial tension. In this work, the interfacial tension is $0.006 \mathrm{~N} \mathrm{~m}^{-1}{ }^{61}$

In a classical stirred mixer-settler, the surface-mean diameter can be calculated by: ${ }^{62}$ 


$$
\begin{aligned}
& \frac{d_{v s}}{D_{i}}=0.052 N_{W e}^{-0.6} e^{4 \emptyset_{d}}, N_{W e}<10000 \\
& \frac{d_{v s}}{D_{i}}=0.39 N_{W e}^{-0.6}, N_{W e}>10000
\end{aligned}
$$

The extraction reaction of cobalt by phosphonium ionic liquid is usually fast; ${ }^{63}$ therefore this work assumes that diffusion is the rate-controlling step in mass transfer. ${ }^{64}$ The overall mass transfer coefficient, $K_{\mathrm{OO}}$, may be calculated from the mass transfer coefficients inside the droplet and in the continuous phase, $k_{\mathrm{IL}}$ and $k_{\mathrm{aq}}$ :

$$
\frac{1}{\mathrm{~K}_{\mathrm{OO}}}=\frac{1}{\mathrm{k}_{\mathrm{IL}}}+\frac{\mathrm{D}}{\mathrm{k}_{\mathrm{aq}}}
$$

Due to the high viscosity of the ionic liquid, the droplet is modelled by Newman's model ${ }^{65}$ and the flow inside the droplet is assumed to be stagnant:

$\mathrm{k}_{\mathrm{d}}=\frac{2 \pi^{2} \mathrm{D}_{\mathrm{diff}, \mathrm{d}}}{\mathrm{d}}$

The mass transfer coefficient in continuous phase is given by: ${ }^{65}$

$\mathrm{k}_{\mathrm{c}}=\frac{2 \mathrm{D}_{\mathrm{diff}, \mathrm{c}}}{\mathrm{d}}$

$\mathrm{D}_{\text {diff,d }}$ and $\mathrm{D}_{\text {diff,c }}$ are diffusion coefficients in the dispersed and continuous phase, respectively.

The aqueous phase diffusion coefficients for the metals are obtained from the literature. ${ }^{66-69}$ The diffusion coefficients for water and the phosphonium cation are also obtained from literature. ${ }^{70}$ As published data for the $\mathrm{HCl}$ diffusion coefficient in $\left[\mathrm{P}_{66614}\right] \mathrm{Cl}$ are lacking, the value is assumed to be the same as that for water. Published values of the diffusion coefficient of some metals in the ionic liquid $\left[\mathrm{P}_{66614}\right] \mathrm{Cl}$ are in the range of $10^{-12}$ to $10^{-11} \mathrm{~m}^{2} \mathrm{~s}^{-1}$. Because data for the diffusion coefficients of cobalt and nickel in $\left[\mathrm{P}_{66614}\right] \mathrm{Cl}$ could not be found, the diffusion coefficients for cobalt and nickel in ionic liquid, are taken to be $1.1 \times 10^{-11} \mathrm{~m}^{2} / \mathrm{s} .{ }^{71}$ The solubility of $\left[\mathrm{P}_{66614}\right] \mathrm{Cl}$ in water is very low; to keep the simulation calculation consistency in the 
simulation code, the diffusion coefficient of $\left[\mathrm{P}_{66614}\right] \mathrm{Cl}$ in aqueous phase is assumed to be the same as that of cobalt in the aqueous phase, which is $1 \times 10^{-9} \mathrm{~m}^{2} / \mathrm{s}$.

The effect of viscosity on the diffusion coefficient in the ionic liquid phase is calculated from Stokes-Einstein equation: ${ }^{60}$

$D_{\text {diff }}=D_{\text {diff }}^{0} \frac{\eta^{0}}{\eta} \cdot \frac{T}{T^{0}}$

Where $D_{\text {diff }}^{0}$ is the diffusion coefficient of the solute in the metal-free (i.e. unloaded) watersaturated ionic liquid for which the viscosity is $\eta^{0}$ and the temperature is $T^{0}$. The values of $D_{\text {diff }}^{0}$ used in this work are listed in Table 2.

Table 2 Diffusion coefficients used in mass transfer model, $\mathrm{m}^{2} \mathrm{~s}^{-1}$

\begin{tabular}{ccccc}
\hline Component & Aqueous phase & Data source & Ionic liquid phase & Data source \\
\hline Cobalt & $1.0 \times 10^{-9}$ & Ribeiro $^{66}$ & $1.1 \times 10^{-11}$ & Matsumiya $^{71}$ \\
Nickel & $1.0 \times 10^{-9}$ & Rard $^{67}$ & $1.1 \times 10^{-11}$ & Assumed \\
$\mathrm{HCl}$ & $5.0 \times 10^{-9}$ & Rizzo $^{68}$ & $1.14 \times 10^{-10}$ & Assumed \\
$\mathrm{H}_{2} \mathrm{O}$ & $5.0 \times 10^{-9}$ & DETHERM $^{69}$ & $1.14 \times 10^{-10}$ & Bayley. $^{70}$ \\
$\left.\mathrm{P}_{66614}\right] \mathrm{Cl}$ & $1.0 \times 10^{-9}$ & Assumed & $2.5 \times 10^{-11}$ & Bayley $^{70}$ \\
\hline
\end{tabular}

\subsection{Mixer-settler Model}

The flows in the stirred mixer are highly turbulent. Therefore, it is assumed that the concentrations of each component in each phase within the mixer are equal to those in the effluent, as in a continuously stirred tank reactor (CSTR). This work also assumes that mixing and mass transfer processes in the mixing zone are isothermal. The ionic liquid and aqueous phases are modelled separately, so the mixer is modelled as having two feeds and two product streams as well as two phases within the mixer. Scheme 2 illustrates the set-up of the unit. 
The model comprises separate material balances for each species in each phase, taking into account material flows and mass transfer:

$\frac{d N_{i}}{d t}=F_{i}^{\text {in }}-F_{i}^{\text {out }}-E_{i}$

$\frac{\mathrm{d} \overline{\mathrm{N}}_{\mathrm{i}}}{\mathrm{dt}}=\overline{\mathrm{F}}_{\mathrm{i}}^{\text {in }}-\overline{\mathrm{F}}_{\mathrm{i}}^{\text {out }}+\mathrm{E}_{\mathrm{i}}$

Scheme 2. Layout of settler unit

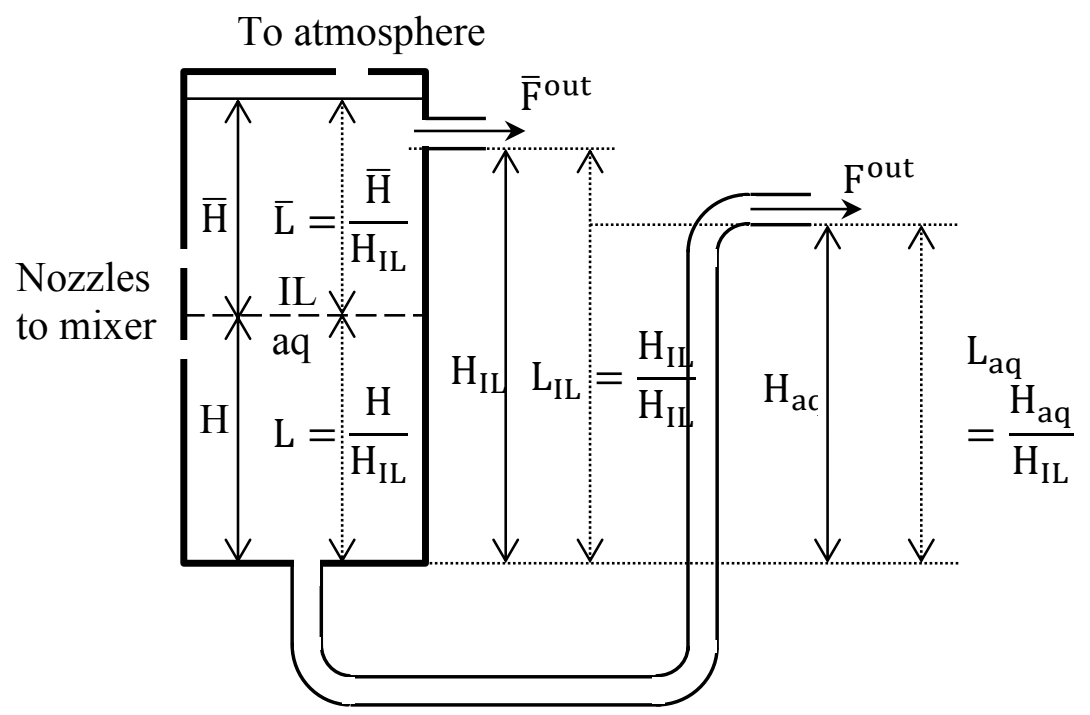

Because the diameter of the extractor is significantly greater than that of the outlet, the total flows out of the aqueous phase, $F^{o u t}$, and ionic liquid phase, $\bar{F}^{\text {out }}$, are controlled by the liquid level and the level of the outlet of each phase: ${ }^{72}$

$\overline{\mathrm{F}}^{\text {out }}=\mathrm{C}_{\mathrm{d}} \sqrt{\left(\mathrm{L}+\overline{\mathrm{L}}-\mathrm{L}_{\mathrm{IL}}\right)}$
$\mathrm{F}^{\text {out }}=\mathrm{C}_{\mathrm{d}} \sqrt{\left(\mathrm{L}+\overline{\mathrm{L}} \cdot \frac{\rho_{\mathrm{IL}}}{\rho_{\mathrm{aq}}}-\mathrm{L}_{\mathrm{aq}}\right)}$

where $C_{d}$ is flow coefficient. $L$ and $\bar{L}$ is the height of the aqueous phase and ionic liquid phase, while $L_{I L}$ and $L_{a q}$ are the levels of the outlet of ionic liquid and aqueous phase relative to the specific liquid level of the extractor, respectively. All these dimensions are relative to the height of the ionic level outlet, as Scheme 2 shows. 


\section{SIMULATION RESULTS AND DISCUSSION}

The model is applied to a case study, based on the work of Wellens et al. ${ }^{27,29}$, who published results of single-stage batch experiments ${ }^{27}$ and continuous multistage experiments ${ }^{29}$ of cobalt and nickel separation by $\left[\mathrm{P}_{66614}\right] \mathrm{Cl}$ from hydrochloric acid solutions. These experiments are used to evaluate the simulation code. Based on experimental equipment ${ }^{27,29}, C_{d}$ is set to $51.6, L_{I L}$ and $L_{a q}$ are 1.0 and 0.95 , respectively.

\subsection{Single-stage Batch Extraction Simulations}

In single stage batch extraction experiments ${ }^{27}, 0.25 \mathrm{~L}$ of each of the feeds - the aqueous solution and ionic liquid - are poured into a $0.5 \mathrm{~L}$ mixer in a 1:1 volumetric ratio; the mixture is stirred for 10 minutes at $60^{\circ} \mathrm{C}$ and then left to settle for $90 \mathrm{~s}$ before being centrifuged to completely separate the two phases. Batch extraction experiment 1 uses pure ionic liquid as the extractant, while in batch extraction experiment 2, the ionic liquid is saturated with $8 \mathrm{M} \mathrm{HCl}$. The composition of the aqueous feed solution of both experiments 1 and 2 is: $5 \mathrm{~g} \mathrm{~L}^{-1}$ cobalt dichloride, $5 \mathrm{~g} \mathrm{~L}^{-1}$ nickel dichloride and $8 \mathrm{~mol} \mathrm{~L}^{-1} \mathrm{HCl}$. The $8 \mathrm{M} \mathrm{HCl}$ presaturated ionic liquid used in experimental 2 is prepared in experiment $2 \mathrm{a}$ in which the aqueous feed solution is $8 \mathrm{M}$ $\mathrm{HCl}$ solution only - no metals are present. ${ }^{27}$

The model presented above is applied to simulate the process, using the same operating parameters as in the experiments ${ }^{27}$. Table 3 presents the simulation results; it may be seen that predicted compositions, density and viscosity of the two phases are in very good agreement with the experimental results.

The simulation model is applied to determine the dynamic behavior of the extractor. Figure 5 shows the profile of cobalt in the ionic liquid phase; the results suggest that mass transfer of 
cobalt in this process is fast, although this still needs to be confirmed experimentally. Figure 5 also shows that the effect of viscosity on mass transfer of cobalt is negligible: the concentration profiles for batch experiment 1 and batch experiment 2 are almost identical. On the other hand, there is an obvious effect of viscosity on the mass transfer of nickel - the mass transfer of nickel in batch experiment 2 is faster than in batch experiment 1 - possibly because the distribution coefficient of nickel is very low.

Table 3 Single-stage batch extraction: predicted performance and experimental results

\begin{tabular}{|c|c|c|c|c|c|c|}
\hline & \multicolumn{2}{|c|}{$\begin{array}{l}\text { Batch extraction } \\
\text { experiment } 1\end{array}$} & \multicolumn{2}{|c|}{$\begin{array}{l}\text { Batch extraction } \\
\text { experiment } 2 \mathrm{a}\end{array}$} & \multicolumn{2}{|c|}{$\begin{array}{l}\text { Batch extraction } \\
\text { experiment } 2\end{array}$} \\
\hline & Simulation & Expt. $^{27}$ & Simulation & Expt. $^{27}$ & Simulation & Expt. $^{27}$ \\
\hline $\mathrm{C}_{\mathrm{Co}}, \mathrm{mg} \mathrm{L}^{-1}$ & 12 & 11 & 0 & 0 & 14 & 14 \\
\hline$\overline{\mathrm{C}}_{\mathrm{Ni}}, \mathrm{mg} \mathrm{L}^{-1}$ & 45 & 44 & 0 & 0 & 43 & 43 \\
\hline$\overline{\mathrm{C}}_{\mathrm{H}_{2} \mathrm{O}}, \mathrm{mol} \mathrm{L}^{-1}$ & 3.73 & 3.89 & 4.21 & 4.35 & 3.62 & 3.49 \\
\hline$\overline{\mathrm{C}}_{\mathrm{HCl}}, \mathrm{mol} \mathrm{L}^{-1}$ & 1.48 & 1.30 & 1.48 & 1.48 & 1.48 & 1.45 \\
\hline $\bar{\eta}, \mathrm{mPa} \mathrm{s}$ & 109 & 101 & 96 & 95 & 110 & 101 \\
\hline $\bar{\rho}, \mathrm{kg} \mathrm{m}^{-3}$ & 904 & 910 & 906 & 900 & 904 & 910 \\
\hline
\end{tabular}

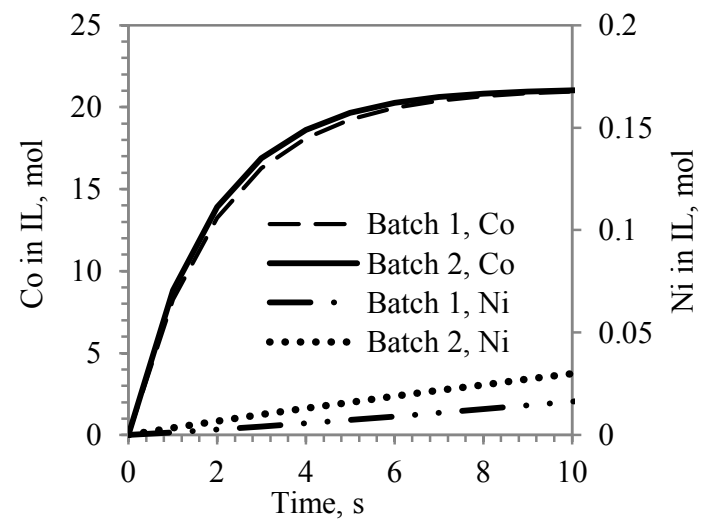

Figure 5 Cumulative extraction of cobalt and nickel in simulated batch extraction process 
Figure 6 shows the predicted viscosity profile of the ionic liquid for these batch extraction simulations. Because the ionic liquid feed in batch extraction 1 is pure ionic liquid, the viscosity of the ionic liquid phase is high at the start of the process. The ionic liquid phase viscosity decreases after water has been extracted into the ionic liquid. On the other hand, the ionic liquid feed in batch extraction 2 is pre-saturated by $8 \mathrm{M} \mathrm{HCl}$ aqueous solution, its viscosity is relatively low at the start of the process. For these two experiments, the final viscosity of the ionic liquid phase is almost identical. When the viscosity profiles of batch experiments 1 and $2 \mathrm{a}$ are compared, it is evident that the absence of metals (in experiment 2a) causes the viscosity to change more quickly, to a lower final value. This result can be explained by the form of extracted cobalt in the ionic liquid, i.e. as $\left[\mathrm{P}_{66614}\right]_{2} \mathrm{CoCl}_{4}$, which has a large viscosity, of up to 15.36 Pa s at $60^{\circ} \mathrm{C} .^{73}$

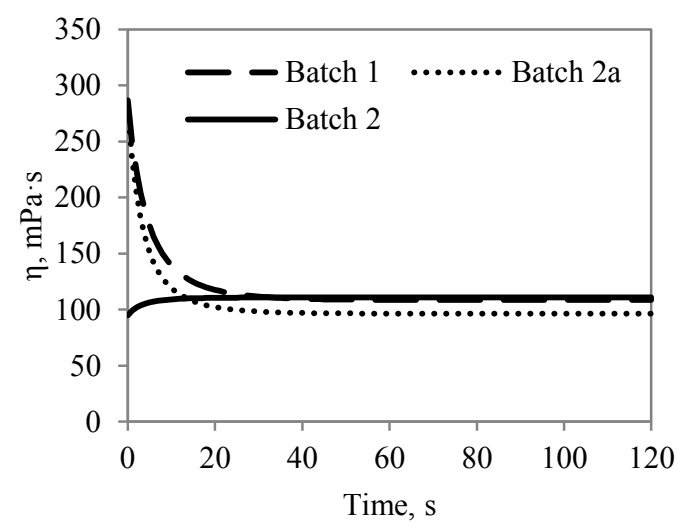

Figure 6 Ionic liquid viscosity profiles of batch extraction simulation 


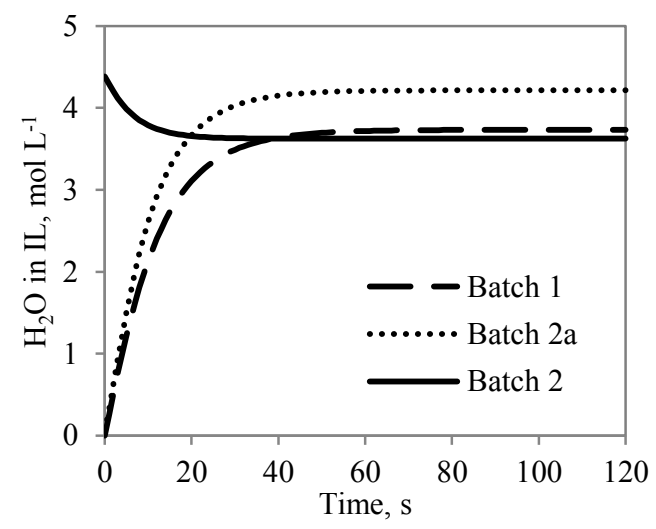

Figure 7 Water in ionic liquid during extraction (simulation results)

Figure 7 shows that the extracted metal can replace or reject the water in the ionic liquid, reducing the water content in the ionic liquid, ${ }^{27,74}$ the lower water content in the ionic liquid phase also causes the viscosity to increase. Figure 8 shows how the volume of the ionic liquid changes during extraction. The simulation result is confirmed by experiments which suggest there is about $15 \%$ volume increase of the ionic liquid phase during extraction, ${ }^{27}$ and is also confirmed when the ionic liquid solution is pre-saturated with aqueous $\mathrm{HCl}$ : in experiment 2, the volumes of both phases remain almost constant during the extraction.

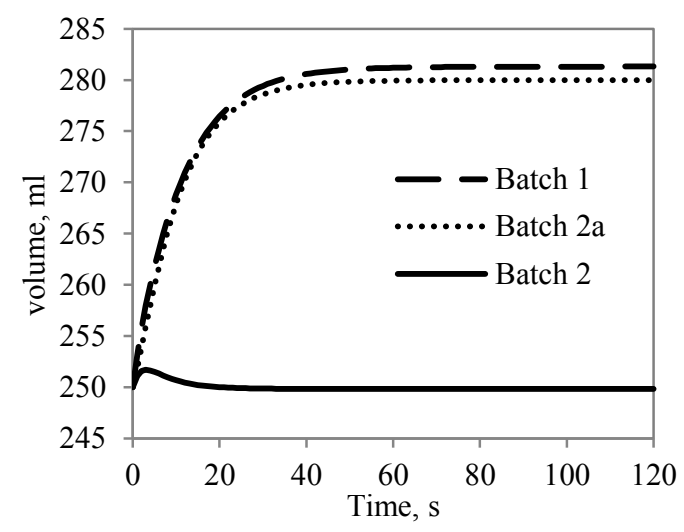

Figure 8 Ionic liquid volume profiles during extraction (simulation results)

\subsection{Multistage Extraction Simulation}


Wellens et al. ${ }^{29}$ published results of a multistage extraction experiment for the separation of cobalt and nickel using ionic liquid $\left[\mathrm{P}_{66614}\right] \mathrm{Cl}$. In this five-stage flowsheet, which is illustrated in Scheme 3, the ionic liquid (IL) is recycled and pure water is used for stripping, so that cobalt and nickel are fully separated from the feed solution. In the experiment ${ }^{29}$, Stages 2 to 5 were initially filled with water and Stage 1 was initially filled with the cobalt-nickel aqueous feed, before the ionic liquid recycle and aqueous solution were successively pumped at controlled flow rates into the first-stage mixer. The flow rates of the water streams entering stages 2 and 5 and that of the recycle were also controlled. The experiment ran for 16 hours after recycling of the ionic liquid started $^{29}$, during which period the product stream compositions were measured. The multistage extraction simulation replicates the experiment in terms of such parameters as feed compositions, flow rates and mixer-settler volumes, and in terms of the operating schedule, in particular the start-up arrangements.

The simulation results for the multistage extraction separation flowsheet are presented in Table 4 and compared with the measured product concentrations. It may be seen that the predictions are in reasonably good agreement with the experimental results. The predicted compositions of the $\mathrm{Ni}$ product from the first extraction stage are within $8 \%$ of the measured values; the compositions of the product of Stage 2 are only within $18 \%$ of the measured values. While relative errors in concentrations of nickel and $\mathrm{P}_{66614}{ }^{+}$in the Co product are large, the absolute errors of those concentrations are small. Some key modeling assumptions and simplifications, such as mass transfer modeling assumptions, the values of the diffusion coefficients and the assumption that mixing, equilibrium and settling are instantaneous, could be responsible for these discrepancies. In addition, discrepancies could arise because of how the operating steps of the published experimental procedure were implemented in the model. 
Scheme 3. Multistage extraction flowsheet ${ }^{29}$

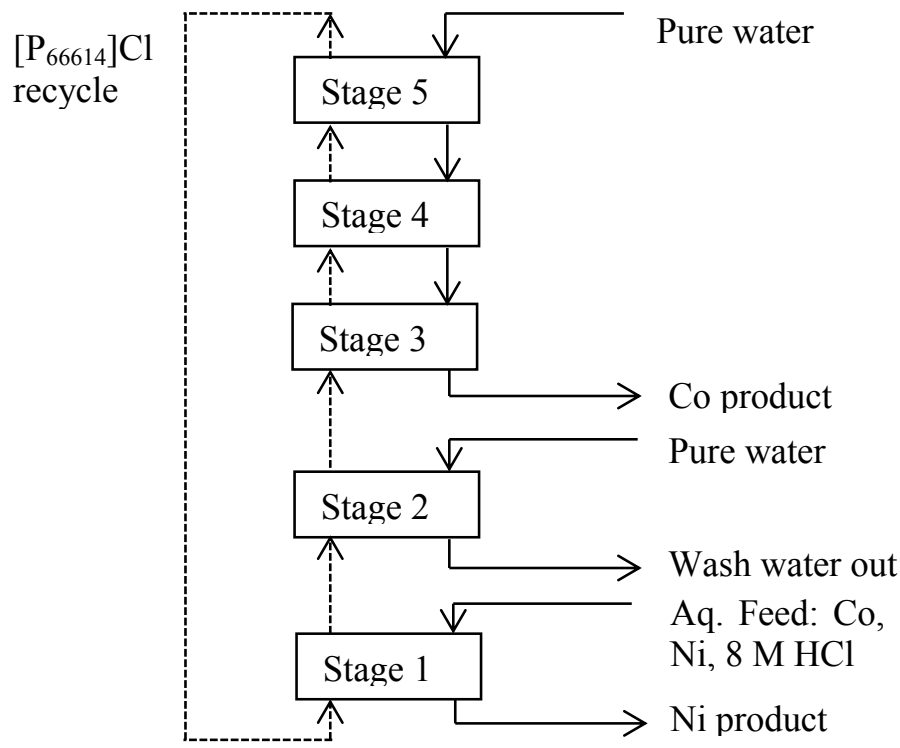

Figure 9 shows the simulated metal concentration profiles in the Co and Ni products. The results suggest that Stage 1 reaches steady state relatively quickly, as would be expected, given its location in the sequence. However, the Ni concentration in the cobalt product is still changing 16 hours after starting to recycle the ionic liquid, only reaching steady state after 24 hours.

Table 4 Multistage extraction flowsheet: predicted performance and experimental results

\begin{tabular}{|c|c|c|c|c|c|}
\hline & & Ni product & Wash water out & Co product & IL recycle \\
\hline \multirow[t]{2}{*}{$\mathrm{Co}, \mathrm{g} \mathrm{L}^{-1}$} & Simulation & 0.019 & 0.296 & 5.942 & 0.048 \\
\hline & Experiment $^{29}$ & 0.021 & 0.250 & 5.000 & 0.055 \\
\hline \multirow[t]{2}{*}{$\mathrm{Ni}, \mathrm{g} \mathrm{L}^{-1}$} & Simulation & 4.866 & 0.083 & 0.001 & $3 \times 10^{-9}$ \\
\hline & Experiment $^{29}$ & 4.900 & 0.100 & 0.007 & Not detected \\
\hline \multirow[t]{2}{*}{$\mathrm{Cl}^{-}, \mathrm{mol} \mathrm{L}^{-1}$} & Simulation & 6.1 & 2.4 & 0.9 & $1.6 \times 10^{-3}$ \\
\hline & Experiment $^{29}$ & 6.4 & 2.8 & 0.8 & Not measured \\
\hline \multirow[t]{2}{*}{$\mathrm{P}_{66614}{ }^{+}, \mathrm{mg} \mathrm{L}^{-1}$} & Simulation & 45 & 45 & 44 & $7.0 \times 10^{5}$ \\
\hline & Experiment $^{29}$ & 43 & 42 & 77 & No report \\
\hline
\end{tabular}




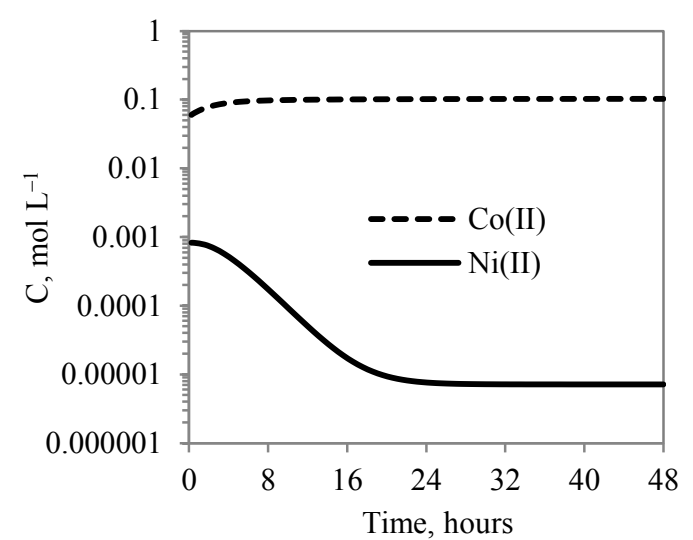

(a)

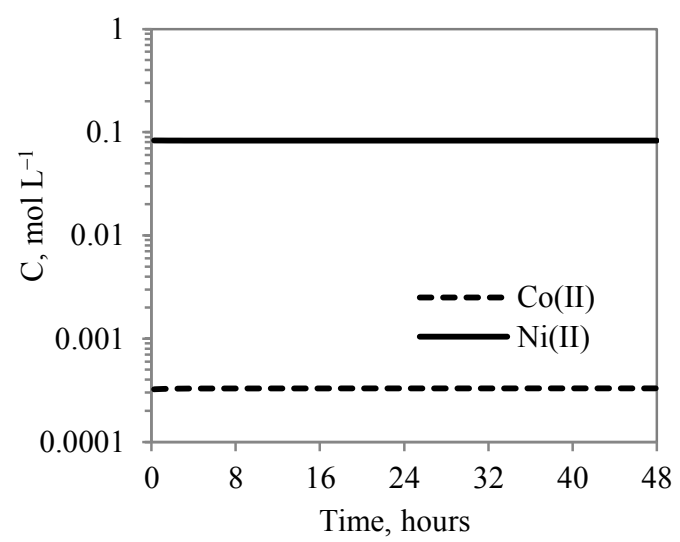

(b)

Figure 9 Metal concentration profiles in (a) Co product and (b) Ni product: simulation results of multistage experiment ${ }^{29}$, extended to 48 hours after starting to recycle the ionic liquid

The results shown in Figure 9 indicate that the operation of the flowsheet stabilizes about 24 hours after starting to recycle the ionic liquid. The calculated extraction rates of cobalt and nickel in each extraction stages, shown in Figure 10, also indicate that steady state will be achieved after that time. Table S2 in the Supporting Information provides further details of steady state simulation results.

The simulation model may be applied to explore the impact of changing process operating parameters on the system dynamics. It is found ${ }^{75}$ that the original experiment might be improved by increasing the flow rates of all feeds and the recycle flow rates up to twice the original values to reduce the time to reach steady state, while still achieving similar separation results and yields. The maximum flow rate would be limited by mass transfer and phase separation rates, as well as by hydraulic constraints.

Although ionic liquid $\left[\mathrm{P}_{66614}\right] \mathrm{Cl}$ is hydrophobic, it is also hygroscopic and slightly soluble in the aqueous phase. The flowsheet simulations predict loss of $\left[\mathrm{P}_{66614}\right] \mathrm{Cl}$ from the extraction flowsheet. For the original operating scheme, the total loss of ionic liquid is about $30 \mathrm{~g}(0.6 \%$ of 
the original amount of ionic liquid added to the system) after running for 55 hours. During this period, $45 \mathrm{~L}$ of cobalt and nickel feed solution, containing around $225 \mathrm{~g}$ each of cobalt and nickel, is separated. The flowsheet model was applied to explore the impact of operating conditions on the loss of ionic liquid: it is found that reducing the flow rate of water helps. However, if the aqueous phase has high metal concentrations, this will lead to high metal loading of the ionic liquid. This high loading will increase the ionic liquid viscosity dramatically ${ }^{27}$, reducing the mass transfer rate. In practice, the Co loading should be no greater than $20 \mathrm{~g} \mathrm{~L}^{-1}{ }^{29}$

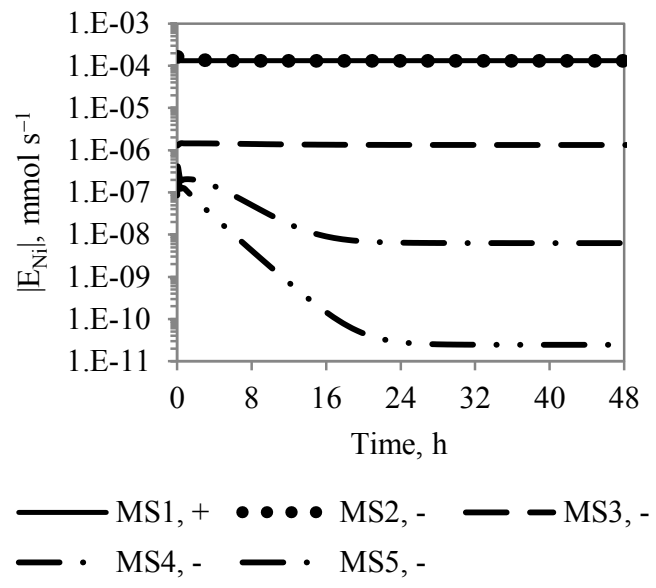

(a)

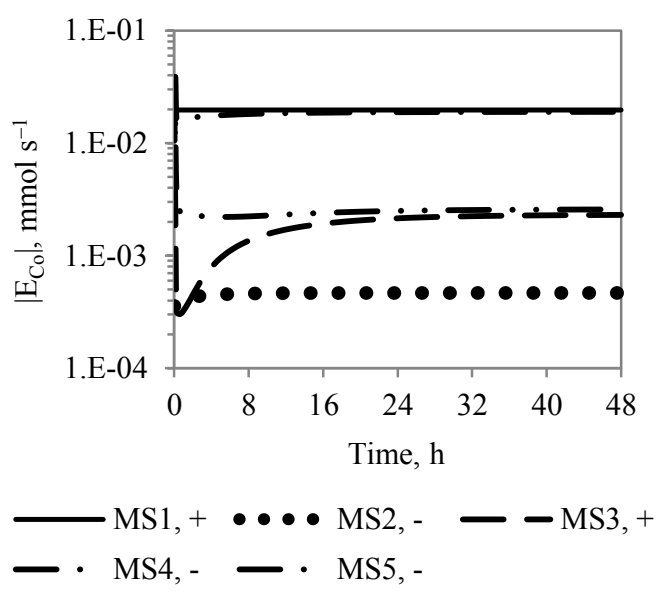

(b)

Figure 10 Metal extraction rates of (a) cobalt and (b) nickel from multistage extraction simulation ("Time": time elapsed since starting to recycle ionic liquid; "+":extraction from aqueous to ionic liquid phase; “-”:extraction from ionic liquid phase to aqueous phase.)

\subsection{Flowsheet Development}

Wellens et al., ${ }^{29}$ reflecting on their multistage experimental studies, suggest how the flowsheet could be improved, in order to remove more of the nickel from the ionic liquid and to reduce loss of Co to the Ni product. Of particular concern is the loss of both Co and Ni, around $250 \mathrm{mg} \mathrm{L}^{-1}$ and $100 \mathrm{mg} \mathrm{L}^{-1}$ respectively, in the wash water outlet. This work proposes three flowsheet 
modifications and applies the simulation model to explore the impact of these changes on the performance of the flowsheet.

Case 1 considers the option of recovering $\mathrm{Co}$ and $\mathrm{Ni}$ from the waste water stream by directly feeding the aqueous phase outlet of Stage 2 to Stage 1, following a suggestion of Wellens et al. ${ }^{29}$ Results for Case 1 are presented in Table 5: the simulation results confirm that recovery of cobalt and nickel to their respective products increases. However, Co is still lost into the Ni product, rather than the wash water outlet and this reduces the purity of the Ni product. Dilution of the aqueous phase in Stage 1 also reduces the concentration of the Ni product. Significantly, this modification also causes $18 \%$ more loss of the ionic liquid, expressed as mass flow rate of ionic liquid lost per unit mass flow rate of metals in the feed stream.

A second modification is proposed to counteract some of the disadvantages of the above configuration. In Case 2, it is proposed to separate out $90 \%$ of the water from the wash water leaving Stage 1 and to add the metal-rich remainder of this stream to Stage 1. The simulation results presented in Table 5 confirms that in Case 2, nickel recovery increases and the recovery of Co can be improved even more than in Case 1, without reducing the purity of the nickel product. The concentration of nickel is only $5 \%$ lower than in the original flowsheet.

The third modification, Case 3, explores the effect of ionic liquid saturated with acid solution in Stage 1, rather than water-saturated ionic liquid, as in the original flowsheet. This modification follows the suggestion of Wellens et al. ${ }^{29}$ of introducing a pretreatment stage to increase the chloride concentration in the ionic liquid which is fed to Stage 1. This pretreatment stage is modeled as an additional extraction stage, in which the recycled ionic liquid is contacted with $8 \mathrm{M} \mathrm{HCl}$ solution before the ionic liquid enters Stage 1. As noted in the discussion of the batch extraction process, the extraction of cobalt into the ionic liquid phase causes water to be 
rejected to the aqueous phase. As a result, the aqueous phase within Stage 1 becomes more dilute with respect to $\mathrm{HCl}$ concentration, and this tends to reduce cobalt extraction. ${ }^{27}$ Presaturating the ionic liquid with $\mathrm{HCl}$ can counteract this effect: the distribution coefficient of cobalt should increase as a result of a higher $\mathrm{HCl}$ concentration in the aqueous phase, and this increase should improve the recovery of cobalt to the ionic liquid phase.

Table 5 Proposed flowsheet modifications: overview of simulation results

\begin{tabular}{cccccccc}
\hline Flowsheet & \multicolumn{2}{c}{ Purity, \% } & \multicolumn{2}{c}{ Recovery, \% } & \multicolumn{2}{c}{ Solution conc., mol L } & IL loss, \\
& Co & Ni & Co & $\mathrm{Ni}$ & Co & Ni & g IL /g metal \\
product & product & product & product & product & product & \\
\hline Original & $>99.9$ & 99.6 & 97.2 & 99.3 & 0.10 & 0.083 & 0.011 \\
flowsheet & $>99.9$ & 99.1 & 99.1 & $>99.9$ & 0.10 & 0.060 & 0.013 \\
Case 1 & $>99.9$ & 99.6 & 99.5 & $>99.9$ & 0.11 & 0.079 & 0.011 \\
Case 2 & $>99.9$ & 99.7 & 99.6 & $>99.9$ & 0.11 & 0.080 & $0.011^{*}$ \\
Case 3 & $>99.9$ &
\end{tabular}

* Loss of ionic liquid in the pre-saturation stage is not considered

When Case 3 is simulated, it is observed that the aqueous phase chloride concentration within Stage 1 does indeed increase (from $6.5 \mathrm{M}$ to $8.0 \mathrm{M}$ ), and the calculated cobalt distribution coefficient increases from 317 to 344 . These changes reduce the cobalt concentration in the nickel product by nearly $10 \%$, from $2.95 \times 10^{-4}$ to $2.67 \times 10^{-4} \mathrm{~mol} \mathrm{~L}^{-1}$, as a result, this pre-saturation operation increases the Ni purity from $99.6 \%$ to $99.7 \%$. A summary of simulation results for Case 3 are presented Table 5. It may be seen that, as expected, the recovery of cobalt increases further, while both recovery and purity of nickel are greater than in the original flowsheet.

\section{CONCLUSION}

This work develops a flowsheet model to simulate the extractive separation of cobalt and nickel using a hydrophobic, non-fluorinated ionic liquid trihexyl(tetradecyl)phosphonium chloride $\left(\left[\mathrm{P}_{66614}\right] \mathrm{Cl}\right)$; no organic diluent is required. This simulation model comprises distribution 
coefficient models, mass transfer models, physical property models and models of the mixersettler units, as well as of the connections between them.

The distribution coefficient models account for the extractive reaction mechanisms, and draws on published experimental data and as well as ab initio predictions using a quantum chemistry COSMO-based method. The mass transfer model estimates the mass transfer rate for given operating conditions, considering density, viscosity, interfacial tension and diffusion coefficients in the mass transfer calculation. Physical properties, including density, viscosity and diffusion, are calculated for the conditions and composition of interest; published data and models are used for this purpose. The mixer-settler is modelled as a continuous stirred tank; two specific cases are modelled, based on the experiments and apparatus reported in the literature. ${ }^{27,29}$

This work successfully applies the flowsheet model to replicate the reported experiments. Single-stage batch extraction and multistage continuous extraction using ionic liquid $\left[\mathrm{P}_{66614}\right] \mathrm{Cl}$ to separate cobalt and nickel are simulated and the predictions are shown to be in good agreement with experimental results.

The accuracy of the model is limited both by simplifications and assumptions of the models and by the lack of data and models for predicting relevant phenomena. In particular, it is assumed that mass transfer is governed by linear driving forces between the continuous phase and the stagnant spherical droplets of known dimension; limited data and models are available for example, related to the water content and density of the ionic liquid and to diffusion coefficients in the multicomponent mixtures of interest. Also, kinetic effects of mixing, reaction and settling are neglected. More reliable experimental data are needed to extend this work. Flowsheet modelling could also benefit from ab initio predictions of property data using modern thermodynamic models, molecular simulations and quantum mechanics-based calculations. 
The flowsheet model is also applied to explore the potential benefits of proposed flowsheet modifications that could increase the recovery and/or purity of the recovered metals. The usefulness of the model for exploring proposed flowsheet modifications, prior to further experimentation, is thus demonstrated.

Future work could evaluate other operating conditions, explore other flowsheet configurations, and potentially other ionic liquids, towards process optimization. Such studies would be essential for commercialisation of this, or similar, novel separation schemes. In addition, the flowsheet model can be further developed to allow its application to other extractive separation processes, such as for the separation of rare earths using ionic liquids.

\section{AUTHOR INFORMATION}

\section{Corresponding Author}

*Hongyan Chen, email: hongyan.chen@manchester.ac.uk.

\section{Author Contributions}

The manuscript was written through contributions of all authors. All authors have given approval to the final version of the manuscript.

\section{Funding Sources}

This work is supported by EPSRC project EP/M029867/1, 'Recycling of rare earths with ionic liquid solvents: Bridging the gap between molecular modelling and process design’.

\section{ACKNOWLEDGMENT}


This work is supported by EPSRC project EP/M029867/1, 'Recycling of rare earths with ionic liquid solvents: Bridging the gap between molecular modelling and process design'. The authors would like to thank Dr Mayri A. Diaz de Rienzo for carrying out experimental measurements.

\section{ASSOCIATED CONTENT}

\section{Supporting Information}

The Supporting Information is available free of charge on the ACS Publications website at DOI: 10.10xx/acs.iecr.xxxxx.

Tables summarizing density data sources and predicted performance and experimental results of the multistage extraction flowsheet.

\section{ORCID}

Hongyan Chen: 0000-0002-9987-8715

Megan Jobson: 0000-0001-9626-5879;

Andrew Masters: 0000-0003-3998-1769;

Maria Gonzalez-Miquel: 0000-0003-3978-8299;

Simon Halstead: 0000-0002-7840-2128;

\section{REFERENCES}

(1) Adoption of the Paris Agreement by the President: Paris Climate Change, 2015; UNFCCC,. http://unfccc.int/resource/docs/2015/cop21/eng/109r01.pdf (accessed Dec 4, 2017).

(2) Binnemans, K.; Jones, P. T.; Blanpain, B.; Gerven, T. V.; Yang, Y.; Walton, A.; Buchert, M. Recycling of Rare Earths: a Critical Review. Journal of Cleaner Production 2013, 51, 1-22.

(3) Tzanetakis, N.; Scott, K. Recycling of Nickel-metal Hydride Batteries. I: Dissolution and Solvent Extraction of Metals. J. Chem. Technol. Biotechnol.J. Chem. Technol. Biotechnol. 2004, 79, 919-926. 
(4) Anderson, C. D.; Anderson, C. G.; Taylor, P. R. Survey of Recycled Rare Earths Metallurgical Processing. Canadian Metallurgical Quarterly 2013, 52, 249-256.

(5) Tunsu, C.; Retegan, T. Hydrometallurgical Processes for the Recovery of Metals from WEEE. In WEEE RECYCLING Research, Development, and Policies; Chagnes, A., Cote, G., Ekberg, C., Nilsson, M., Retegan, T., Eds.; Elsevier Inc.: Amsterdam, 2016; pp 139-175.

(6) Fernandes, A.; Afonso, J. C.; Dutra , A. J. B. Separation of Nickel(II), Cobalt(II) and Lanthanides from Spent Ni-MH Batteries by Hydrochloric Acid Leaching, Solvent Extraction and Precipitation. Hydrometallurgy 2013, 133, 37-43.

(7) Flett, D. S. Cobalt-Nickel Separation in Hydrometallurgy: a Review. Chemistry for sustainable development 2004, 12, 81-91.

(8) Vandermeersch, T.; Gevers, L.; De Malsch, W. A Robust Multistage Mesoflow Reactor for Liquid-liquid Extraction for the Separation of Co/Ni with Cyanex 272. Sep. Purif. Technol. 2016, 168, 32-38.

(9) Park, K. H.; Mohapatra, D. Process for Cobalt Separation and Recovery in the Presence of Nickel from Sulphate Solutions by Cyanex 272. Metals and Materials International 2006, 12, 441-446.

(10) Ichlas, Z. T.; Ibana, D. C. Process Development for the Direct Solvent Extraction of Nickel and Cobalt from Nitrate Solution: Aluminum, Cobalt, and Nickel Separation using Cyanex 272. International Journal of Minerals, Metallurgy, and Materials 2017, 24, 37-46. 
(11) Regel-Rosocka, M.; Materna, K. Ionic Liquids for Separation of Metal Ions and Organic Compounds from Aqueous Solutions. In Ionic Liquids in Separation Technology, 1st ed.; De Los Ríos, A. P., Hernández-Fernández, F. J., Eds.; Elsevier B.V.: Amsterdam, 2014; pp153-188.

(12) Chen, J., Ed. Application of Ionic Liquids on Rare Earth Green Separation and Utilization; Springer: Heidelberg, Germany, 2015.

(13) Zhu, M.; Zhao, J.; Li, Y.; Mehio, N.; Qi, Y.; Liu, H.; Dai, S. An Ionic Liquid-based Synergistic Extraction Strategy for Rare Earths. Green Chem. 2015, 17, 2981-2993.

(14) Wang, W.; Yang, H.; Cui, H.; Zhang, D.; Liu, Y.; Chen, J. Application of Bifunctional Ionic Liquid Extractants [A336][CA-12] and [A336][CA-100] to the Lanthanum Extraction and Separation from Rare Earths in the Chloride Medium. Ind. Eng. Chem. Res. 2011, 50, 75347541.

(15) Shen, Y.; Wu, J.; Liu, Z.; Wu, W. Environmentally Friendlier Approach to Nuclear Industry: Recovery of Uranium from Carbonate Solutions Using Ionic Liquids. Ind.Eng. Chem. Res. 2015, 54, 8624-8628.

(16) Parmentier, D.; Paradis, S.; Metz, S. J.; Wiedmer, S. K.; Kroon, M. C. Continuous Process for Selective Metal Extraction with an Ionic Liquid. Chem. Eng. Res. Des. 2016, 109, 553-560.

(17) Fraser, K. J.; MacFarlane, D. R. Phosphonium-Based Ionic Liquids: An Overview. Aust. J. Chem. 2009, 62, 309-321.

(18) Regel-Rosocka, M. Extractive Removal of Zinc(II) from Chloride Liquors with Phosphonium Ionic Liquids/toluene Mixtures as Novel Extractants. Sep. Purif. Technol. 2009, $66,19-24$. 
(19) Quinn, J. E.; Ogden, M. D.; Soldenhoff, K. Solvent Extraction of Uranium(VI) from Chloride Solutions using Cyphos IL-101. Solvent Extraction and Ion Exchange 2013, 31, 538549.

(20) Kogelnig, D.; Stojanovic, A.; Jirsa, F.; Körner, W.; Krachler, R.; Keppler, B. K. Transport and Separation of Iron(III) from Nickel(II) with the Ionic Liquid Trihexyl(tetradecyl)phosphonium Chloride. Sep. Purif. Technol. 2010, 72, 56-60.

(21) Guibal, E.; Campos Gavilan, K.; Bunio, P.; Vincent, T.; Trochimczuk, A. CYPHOS IL 101 (Tetradecyl(Trihexyl)Phosphonium Chloride) Immobilized in Biopolymer Capsules for Hg(II) Recovery from HCl Solutions. Sep. Sci. Technol. 2008, 43, 2406-2433.

(22) Rybka, P.; Regel-Rosocka, M. Nickel(II) and Cobalt(II) Extraction from Chloride Solutions with Quaternary Phosphonium Salts. Sep. Sci. Technol. 2012, 47, 1296-1302.

(23) Zhu, Z.; Yoko, P.; Cheng, C. Y. Recovery of Cobalt and Manganese from Nickel Laterite Leach Solutions Containing Chloride by Solvent Extraction using Cyphos IL 101. Hydrometallurgy 2017, 169, 213-218.

(24) Riaño, S.; Binnemans, K. Extraction and Separation of Neodymium and Dysprosium from used NdFeB Magnets: an Application of Ionic Liquids in Solvent Extraction Towards the Recycling of Magnets. Green Chem. 2015, 17, 2931-2942.

(25) Vander Hoogerstraete, T; Wellens, S.; Verachtert, K.; Binnemans, K. Removal of Transition Metals from Rare Earths by Solvent Extraction with an Undiluted Phosphonium Ionic Liquid: Separations Relevant to Rare-earth Magnet Recycling. Green Chem. 2013, 15, 919-927. 
(26) Neves, C. M. S. S.; Carvalho, P. ; Freire, M. G.; Coutinho, J. Thermophysical Properties of Pure and Water-saturated Tetradecyltrihexylphosphonium-based Ionic Liquids. J. Chem. Thermodynamics 2011, 43, 948-957.

(27) Wellens, S.; Thijs, B.; Binnemans, K. An Environmentally Friendlier Approach to Hydrometallurgy: Highly Selective Separation of Cobalt from Nickel by Solvent Extraction with Undiluted Phosphonium Ionic Liquids. Green Chem. 2012, 14, 1657-1665.

(28) Cui, L.; Cheng, F.; Zhou, J. Behaviors and Mechanism of Iron Extraction from Chloride Solutions Using Undiluted Cyphos IL 101. Ind. Eng. Chem. Res. 2015, 54, 7534-7542.

(29) Wellens, S.; Goovaerts, R.; Moller, C.; Luyten, J.; Thijs, B.; Binnemans, K. A Continuous Ionic Liquid Extraction Process for the Separation of Cobalt from Nickel. Green Chem. 2013, $15,3160-3164$.

(30) Law, J.; Rutledge, V.; Pereira, C.; Copple, J.; Frey, K.; Krebs, J.; Maggos, L.; Nichols, K.; Wardle, K.; Sadasivan, P.; de Almeida, V.; DePaoli, D. Requirements for a Dynamic Solvent Extraction Module to Support Development of Advanced Technologies for the Recycle of Used Nuclear Fuel; INL/EXT-11-22473; Idaho National Laboratory: Idaho National Falls, ID, 2011.

(31) Mitchell, A. D. SEPHIS-MOD4: A User's Manual to a Revised Model of the PUREX Solvent Extraction System.; ORNL-5471; Oak Ridge National Laboratory: Oak Ridge, TN, 1979.

(32) Tachimori, S. EXTRA.M: A Computer Code System for Analysis of the Purex Process with Mixer Settlers for Reprocessing; JAERI-1331; Japan Atomic Energy Research Institute, Tokyo, Japan, 1993. 
(33) Bjerrum, J.; Halonin, A. S.; Skibsted, L. H. Studies on Cobalt(II) Halide Complex Formation. I. A Spectrophotometric Study of the Chloro Cobalt(II) Complexes in Strong Aqueous Chloride Solutions. Acta Chemica Scandinavica A 1975, 29, 326-332.

(34) Lee, M.-S.; Oh, Y.-J. Chemical Equilibria in a Mixed Solution of Nickel and Cobalt Chloride. Mater. Trans. 2005, 46, 59-63.

(35) Sato, T.; Adachi, K.; Kato, T.; Nakamura, T. The Extraction of Divalent Manganese, Cobalt, Copper, Zinc, and Cadmium from Hydrochloric Acid Solutions by Tri-n-octylamine. Sep. Sci. Technol. 1982, 17, 1565-1576.

(36) Dupont, D.; Depuydt, D.; Binnemans, K. Overview of the Effect of Salts on Biphasic Ionic Liquid/Water Solvent Extraction Systems: Anion Exchange, Mutual Solubility, and Thermomorphic Properties. J. Phys. Chem. B 2015, 119, 6747-6757.

(37) Stokes, R. H. Thermodynamics of solutions. In Activity Coefficients in Electrolyte Solutions, Vol.1; Pytkowicz, R. M., Ed.; CRC Preaa, Inc.: Boca Raton, FL, 1979; pp 27.

(38) Sato, T.; Shimomura, T.; Murakami, S.; Maeda, T.; Nakamura, T. Liquid-liquid Extraction of Divalent Manganese, Cobalt, Copper, Zinc and Cadmium from Aqueous Chloride Solutions by Tricaprylmethylammonium Chloride. Hydrometallurgy 1984, 12, 245-254.

(39) Deferm, C.; Van de Voorde, M.; Luyten, J.; Oosterhof, H.; Fransaer, J.; Binnemans, K. Purification of Indium by Solvent Extraction with Undiluted Ionic Liquids. Green Chem. 2016, $18,4116-4127$.

(40) Good, M. L.; Bryan, S. E.; Holland, J. F. F.; Maus, G. J. Nature of the Hydrogen Ion Effect on the Extraction of Co(II) from Aqueous Chloride Media by Substituted Ammonium 
Chlorides of High Molecular Weight. Journal of Inorganic and nuclear chemistry 1963, 25, 1167-1173.

(41) Trulove, P. C.; Haworth, D.; Carlin, R. T.; Soper, A. K.; Ellison, A. J. G.; Price, D. L. Structural Investigations of 1-ethyl-3-methylimidazolium Hydrogen Dichloride: Neutron Diffraction Studies of an Ambient-temperature Molten Salt. In Proceedings of the Ninth International Symposium on Molten Salts, San Francisco, CA, May 22-27, 1994; Hussey, C. L., Newman, D. S., Mamantov, G., Ito, Y., Eds, Electrochemical Society, Pennington, NJ, 1994; pp50-57

(42) Del Popolo, M. G.; Kohanoff, J.; Lynden-Bell, R. M. Solvation Structure and Transport of Acidic Protons in Ionic Liquids: a First-principles Simulation Study. J. Phys. Chem. B 2006, 110, 8798-8803.

(43) Vander Hoogerstraete, T.; Binnemans, K. Highly Efficient Separation of Rare Earths from Nickel and Cobalt by Solvent Extraction with the Ionic Liquid Trihexyl(tetradecyl)phosphonium Nitrate: a Process Relevant to the Recycling of Rare Earths from Permanent Magnets and Nickel Metal Hydride Batteries. Green Chem. 2014, 16, 1594-1606.

(44) Lefrou, C.; Fabry, P.; Poignet, J.-C. Electrochemistry - The Basics, with Examples; Springer: Heidelberg, Germany, 2012; pp 132-135

(45) Partanen, J. I.; Juusola, P. M.; Vahteristo, K. P.; de Mendonça, A. J. G. Re-evaluation of the Activity Coefficients of Aqueous Hydrochloric Acid Solutions up to a Molality of $16.0 \mathrm{~mol} \cdot \mathrm{kg}^{-1}$ Using the Hückel and Pitzer Equations at Temperatures from 0 to $50{ }^{\circ} \mathrm{C}$. Journal of Solution Chemistry 2007, 36, 39-59. 
(46) Mesmer, R. E.; Holmes, H. F. pH, Definition and Measurement at High Temperatures. Journal of Solution Chemistry 1992, 21 (8), 725-744.

(47) Archer, D. G.; Wang, P. The Dielectric Constant of Water and Debye-Hückel Limiting Law Slopes. Journal of Physical and Chemical Reference Data 1990, 19, 371-411.

(48) Klamt, A. The COSMO and COSMO-RS Solvation Models. Wiley Interdisciplinary Reviews: Computational Molecular Science 2011, 1, 699-709.

(49) Diedenhofen, M.; Klamt, A. COSMO-RS as a Tool for Property Prediction of IL mixtures-A Review. Fluid Phase Equilib. 2010, 294, 31-38.

(50) Freire, M. G.; Ventura, S. P. M.; Santos, L. M. N. B. F.; Marrucho, I. M.; Coutinho, J. A. P. Evaluation of COSMO-RS for the Prediction of LLE and VLE of Water and Ionic Liquids Binary Systems. Fluid Phase Equilib. 2008, 268, 74-84.

(51) Ferro, V. R.; de Riva, J. ; Sanchez, D.; Ruiz, E.; Palomar, J. Conceptual Design of Unit Operations to Separate Aromatic Hydrocarbons from Naphtha using Ionic Liquids. COSMOBased Process Simulations with Multi-component "real" Mixture Feed. Chem. Eng. Res. Des. 2015, 94, 632-647.

(52) Äkerlöf, G.; Teare, J. A Note on the Density of Aqueous Solutions of Hydrochloric Acid. Journal of the American Chemical Society 1938, 60, 1226-1228.

(53) Pogue, R.; Atkinson, G. Solution Thermodynamics of First-Row Transition Elements. 1. Apparent Molal Volumes of Aqueous $\mathrm{NiCl}_{2}, \mathrm{Ni}\left(\mathrm{ClO}_{4}\right)_{2}, \mathrm{CuCl}_{2}$, and $\mathrm{Cu}\left(\mathrm{ClO}_{4}\right)_{2}$ from 15 to $55^{\circ} \mathrm{C}$. J. Chem. Eng. Data 1988, 33, 370-376. 
(54) Herrington, T. M.; Roffey, M. G.; Smith, D. P. Densities of Aqueous Electrolytes $\mathrm{MnCl}_{2}$, $\mathrm{CoCl}_{2}, \mathrm{NiCl}_{2}, \mathrm{ZnCl}_{2}$, and $\mathrm{CdCl}_{2}$, from 25 to $72{ }^{\circ} \mathrm{C}$ at 1 atm. J. Chem. Eng. Data 1986, 31, 221225.

(55) Pogue, R. F.; Atkinson, G. Solution Thermodynamics of First-Row Transition Elements.

2. Apparent Molal Volumes of Aqueous $\mathrm{MnCl}_{2}, \mathrm{Mn}\left(\mathrm{ClO}_{4}\right)_{2}, \mathrm{CoCl}_{2}, \mathrm{Co}\left(\mathrm{ClO}_{4}\right)_{2}, \mathrm{FeCl}_{2}$, and $\mathrm{Fe}\left(\mathrm{ClO}_{4}\right)_{2}$, from 15 to $55^{\circ} \mathrm{C} . J$. Chem. Eng. Data 1989, 34, 227-232.

(56) DECHEMA Thermophysical Property Database. http://detherm.cds.rsc.org/detherm/ (accessed Sept 27, 2016).

(57) Tsubata, Y.; Asakura, T.; Morita, Y. Development of a Computer Code, PARC, for Simulation of Liquid-liquid Extraction Process in Reprocessing; JAEA-DATA/CODE--2008010; Japan Atomic Energy Agency: Tokai-mura, Naka-gunm Ibaraki-ken, Japan, 2008.

(58) Dinh, B. Investigation of the Extraction Kinetics of Uranium Nitrate by Tributyl Phosphate: Application of the Single Drop Method in Pulsed Medium; CEA-R-5414; CEA Centre d'Etudes Nucleaires de Fontenay-aux-Roses: Chatenay-Malabry , France, 1987.

(59) Chen, H.; Taylor, R. J.; Jobson, M.; Woodhead, D. A.; Masters, A. J. Development and Validation of a Flowsheet Simulation Model for Neptunium Extraction in an Advanced PUREX Process. Solven Extraction and Ion Exchange 2016, 34, 297-321.

(60) Seader, J. D.; Henley, E. J. Separation process principles, $2^{\text {nd }}$ ed.; John Wiley \& Sons, Inc.: New York, 1998; pp 471.

(61) Carrera, G. V. S. M.; Afonso, C. A. M.; Branco, L. C. Interfacial Properties, Densities, and Contact Angles of Task Specific Ionic Liquids. J. Chem. Eng. Data 2010, 55, 609-615. 
(62) Gnanasundaram, S.; Degallesan, T. E.; Laddha, G. S. Prediction of Mean Drop Size in Batch Agitated Vessels. The Canadian Journal of Chemical Engineering 1979, 57, 141-144.

(63) Atefi, F.; Garcia, M. T.; Singer, R. D.; Scammells, P. J. Phosphonium Ionic liquids: Design, Synthesis and Evaluation of Biodegradability. Green Chem. 2009, 11, 1595-1604.

(64) Marszalkowska, B.; Sobczynska, A.; Wisnieweki, M. Kinetics of Zinc and Iron Ion Extraction from Acidic Solutions with Phosphonium Ionic Liquid. In Proceedings of XXIII International Symposium on Physico-Chemical Methods of Separation "Ars Separatoria 2008", Toruń, Poland, July 6-9, 2008; Koter, S., Koter, I., Eds., Nicolaus Copernicus University in Toruń, Toruń, Poland, 2008; pp 52-55

(65) Newman, A. B. The Drying of Porous Solids: Diffusion Calculations. Transactions of the American Insitute of Chemical Engineers 1931, 27, 310-333.

(66) Ribeiro, A. C. F.; Lobo, V. M. M.; Natividade, J. J. S. Diffusion Coefficients in Aqueous Solutions of Cobalt Chloride at 298.15K. J. Chem. Eng. Data 2002, 47, 539-541.

(67) Rard, J. A.; Miller, D. G.; Lee, C. M. Mutual Diffusion Coefficients of NiCl,-H,O at 298.15 K from Rayleigh Interferometry. Journal of the Chemical Society, Faraday Transactions 1: Physical Chemistry in Condensed Phases 1989, 85, 3343-3352.

(68) Rizzo, P.; Albright, J. G.; Miller, D. G. Measurements of interdiffusion coefficients and densities for the system $\mathrm{HCl}+\mathrm{H}_{2} \mathrm{O}$ at $25^{\circ} \mathrm{C}$. J. Chem. Eng. Data 1997, 42, 623-630.

(69) DECHEMA Thermophysical Property Database. http://detherm.cds.rsc.org/detherm (accessed Nov 30, 2016). 
(70) Bayley, P. M.; Novak, J.; Khoo, T.; Britton, M. M.; Howlett, P. C.; Macfarlane, D. R.; Forsyth, M. The influence of water and metal ions on the transport properties of trihexyl(tetradecyl)phosphonium chloride. Aust. J. Chem. 2012, 65, 1542-1547.

(71) Matsumiya , M.; Suda, S.; Tsunashima, K.; Sugiya, M.; Kishioka, S.-y.; Matsuura, H. Electrochemical behaviors of multivalent complexes in room temperature ionic liquids based on quaternary phosphonium cations. J. Electroanal. Chem. 2008, 622, 129-135.

(72) Guyon, E.; Hulin, J. P.; Petit, L.; Mitescu, C. D. Physical Hydrodynamics, $2^{\text {nd }}$ ed.; Oxford University Press: Oxford, 2015;pp 155.

(73) Santos, E.; Albo, J.; Rosatella, A.; Irabien, Á. Synthesis and Characterization of Magnetic Ionic Liquids (MILs) for $\mathrm{CO}_{2}$ Separation. J. Chem. Technol. Biotechnol. 2014, 89, 866-871.

(74) Sato, T. S. The Extraction of Anionic Complexes of Divalent Manganese, Cobalt, Nickel and Copper from Aqueous Thiocyanate, Solutions by Tricaprylmethylammonium Chloride. $J$. Chem. Tech. Biotechnol. 1979, 29, 39-50.

(75) Chen, H.; Jobson, M. Flowsheet Simulation of Cobalt-Nickel Separation Using Ionic Liquid Cyphos 101. In Produceedings of the 27th European Symposium on Computer ided Process Engineering, Part A, Barcelona, Oct.1-5, 2017; Espuna, A., Graells, M., Puigjaner, L. Eds., Elsevier, Amsterdam, 2017; pp 373-378 
TOC graphic:

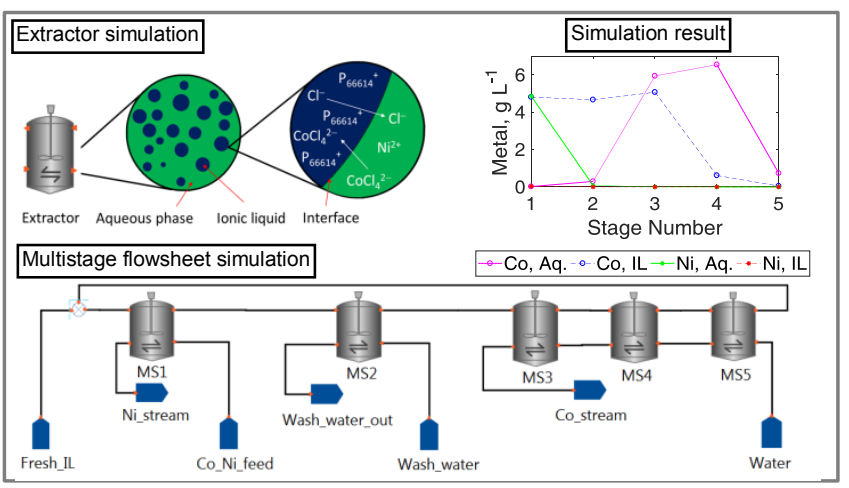

